\title{
Implementation of a High Performance Permanent Magnet Synchronous Drive with Reduced Switching Frequency and Loss
}

\author{
Tian-Hua Liu \\ Chih-Jung Chen \\ 43. Section 4, keelung Road, \\ Taipei 106, Taiwan
}

Department of Electrical Engineering

National Taiwan University of Science and Technology

\begin{abstract}
This paper proposes an improved permanent magnet synchronous drive system. By suitably adjusting the three-phase current commands, the switching frequency of the drive system can be abruptly reduced. In addition, the three-phase currents maintain balanced sinusoidal waveforms. An optimal control is designed to achieve high performance dynamic responses which include a fast transient response and a good load disturbance rejection capability. A 16-bit microprocessor system (MC 80196) is used to execute the improved control algorithm. Several experimental results validate the theoretical analysis. This paper presents a new direction in the design and implementation of a permanent magnet synchronous drive system.
\end{abstract}

\section{INTRODUCTION}

Permanent magnet synchronous motor (PMSM) drive technology has been widely used in industry. The PMSM drive system has many advantages. For example, it has a higher torque to inertia ratio, superior power density, and higher efficiency than other ac drives. In addition, there is no slip between its stator and rotor. The torque control, therefore, is simpler. There have been many studies on the PMSM drive system [1]- [4]. These papers discussed the PMSM motor and its drive system. However, to the authors' best knowledge, the reduced switching frequency method and the optimal controller have not previously been applied to improve the performance of the PMSM drive This paper, therefore, proposes methods to achieve the above mentioned goals.

\section{THE PMSM DRIVE SYSTEM}

Fig. 1 shows the block diagram of the proposed speedcontrol system. The system consists of two major parts: a microprocessor system and some hardware circuits. The

This paper is supported by National Science Council, under Grant NSC 86-2213-E-011-076

\author{
Bin-Yen Ma \\ Wu-Shiung Feng \\ Department of Electrical Engineering \\ National Taiwan University \\ 1, Section 4, Roosevelt Road, \\ Taipei 106, Taiwan
}

microprocessor is used to execute the optimal controller,the coordinate transformation, and the minimized switching frequency. The hardware circuits include a resonant dc-link inverter, a current regulator, feedback sensors, and a PMSM. First, the microprocessor reads the digital shaft position signal. Then, the microprocessor executes the $d-q$ to $a-b-c$ coordinate transformation. Next, the microprocessor carries out the minimized switching frequency algorithm, and outputs the three-phase current commands $i_{a}^{*}, i_{b}^{*}$, and $i_{c}^{*}$ to the hardware circuits. The inverter is a resonant dc-link inverter. A current regulator is designed to insure that the real currents follow the current commands. The current regulator controls the inverter causing it to switch when the output voltage of the resonant dc-link converter is close to zero. A zero voltage switching is thus obtained. The three-phase currents drive the PMSM, and a closed-loop system is achieved.

In order to obtain good dynamic performance, an optimal controller is designed. By setting a performance index, the parameters of the feedback gain can be systematically computed. Although the derivation of the control law is complicated, it is easily implemented by the microprocessor. In addition, the minimized switching frequency method is proposed here to reduce the switching frequency of the inverter. This minimized method is easily implemented by the microprocessor.

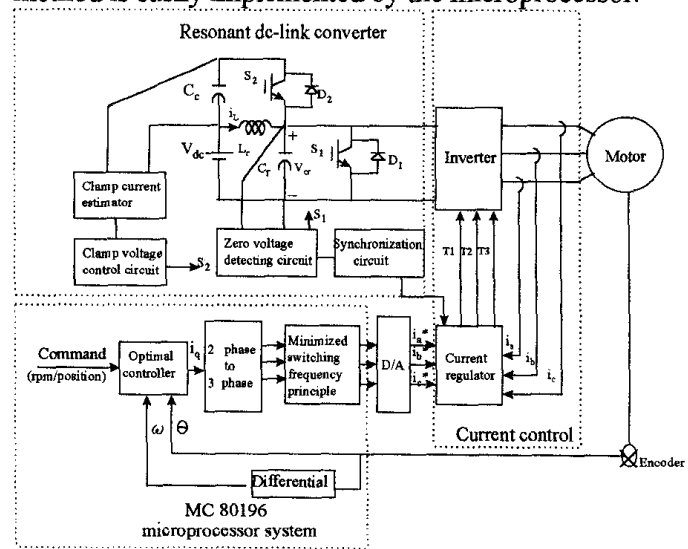

Fig. 1 The block diagram of the proposed system. 


\section{RESONANT DC-LINK INVERTER}

The resonant dc-link inverter circuit is shown in Fig. 2(a). The circuit consists of two major parts: a resonant dc-link converter and an inverter. The resonant dc-link converter, which is shown in Fig. 2(a), is composed of a resonant LC circuit, a zero voltage detecting circuit, a synchronization circuit, a clamp current estimator, and a clamp voltage control circuit [5]-[6] First, a zero voltage detecting circuit is designed to detect the instant when the resonant converter reaches zero voltage. Then, the switch $S_{1}$ is shorted to give the inductance enough energy. After the switch $S_{1}$ is opened, the LC circuit resonates. As the voltage of the resonant capacitor increases and reaches the setting clamp voltage, the clamp switch $S_{2}$ is closed. Then, the energy is pumped into the clamp capacitor $C_{c}$ and the voltage of the resonant capacitor is clamped. The clamp current estimator is designed to estimate the current of the clamp circuit. By suitably controlling the clamp switch $S_{2}$, the energy flowing into and out the clamp capacitor $C_{c}$ is balanced. The synchronization circuit is used to switch the inverter while the output voltage of the resonant dclink converter is close to zero. Fig. 2(b) shows the voltage of the resonant capacitor.

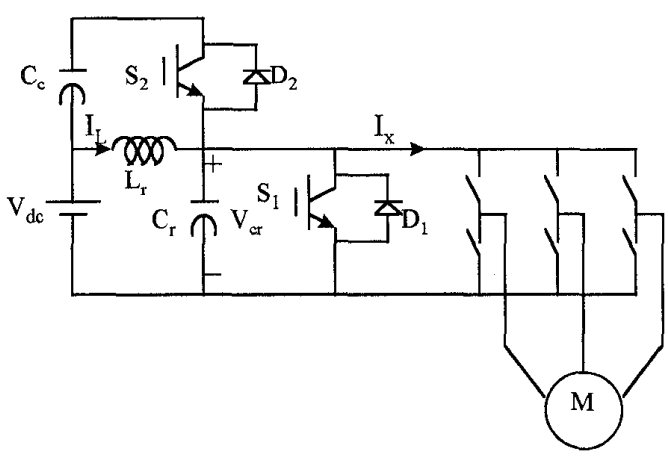

(a)

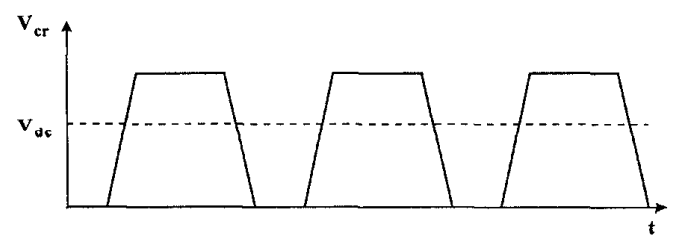

(b)

Fig. 2 The resonant dc-link inverter (a)circuit (b)output voltage.

\section{OPTIMAL CONTROLLER DESIGN}

The optimal controller is designed by setting a performance index I as

$$
I=\frac{1}{2} \int_{0}^{t_{f}}\left(X^{T}(t) Q X(t)+U^{\mathrm{T}}(t) R_{1} U(t)\right) d t,
$$

where $Q$ is a real semipositive matrix, $R_{1}$ is a real positive matrix, $X$ is the state variable, and $u$ is the control input. If $\mathrm{Q}$ is selected as a matrix with larger values, then the responses are more important than the input energy. On the other hand, if $R_{1}$ is selected as a matrix with larger values, then the energy becomes more important.

The equivalent system, which consists of a shaping filter, a speed-loop controller, and a brushless motor, can be expressed as:

$$
\begin{aligned}
& \dot{X}=A X(t)+B U(t), \\
& Y(t)=C X(t),
\end{aligned}
$$

where $A, B, C$ are the parameters of the equivalent system, and $Y(t)$ is the output of the system.

and

$$
\mathrm{A}=\left[\begin{array}{ccc}
-\frac{B_{m}}{J_{m}} & \frac{\mathrm{k}_{\mathrm{t}} \mathrm{k}_{\mathrm{e}}}{J_{m}} & 0 \\
-k_{2}+\frac{B_{m} \mathrm{k}_{\mathrm{p} 2}}{J_{m}} & -\frac{\mathrm{k}_{\mathrm{p} 2} \mathrm{k}_{\mathrm{t}} \mathrm{k}_{\mathrm{e}}}{J_{m}} & \mathrm{k}_{\mathrm{i} 2}-\frac{\mathrm{k}_{\mathrm{p} 2}}{\mathrm{k}_{\mathrm{i} 1}} \\
0 & 0 & -\frac{1}{\mathrm{k}_{\mathrm{i} 1}}
\end{array}\right]
$$

$$
\mathrm{B}=\left[\begin{array}{c}
0 \\
\mathrm{k}_{\mathrm{p} 2} \mathrm{k}_{\mathrm{pl}} \\
\mathrm{k}_{\mathrm{i} 1} \\
\frac{\mathrm{k}_{\mathrm{p} 1}}{\mathrm{k}_{\mathrm{i} 1}}
\end{array}\right],
$$

$$
\mathrm{C}=\left[\begin{array}{lll}
1 & 0 & 0
\end{array}\right]
$$

$$
X=\left[\begin{array}{l}
x_{1} \\
x_{2} \\
x_{3}
\end{array}\right],
$$

where $B_{m}$ is the viscous coefficient, $J_{m}$ is the inertia, $\mathrm{K}_{\mathrm{t}}$ is the torque constant, $\mathrm{K}_{\mathrm{e}}$ is the back emf coefficient, $\mathrm{K}_{\mathrm{p} 2}, \mathrm{~K}_{\mathrm{i} 2}$ are the parameters of the speed-loop controller, $\mathrm{K}_{\mathrm{il}}, \mathrm{K}_{\mathrm{p} 1}$ are the parameters of the shaping filter, and $x_{1}$, 
$\mathrm{X}_{2}, \mathrm{X}_{3}$ are the state variables. The real system should satisfy the following constraints

$$
\begin{gathered}
|U(\mathrm{t})| \leq U_{\max }, \\
|X(t)| \leq X_{\max }
\end{gathered}
$$

Then from equations (1) and (2), we can derive the optimal control input $U^{*}(\mathrm{t})$ as follows:

$$
\begin{aligned}
& U^{*}(\mathrm{t})=-K_{m o} X^{*}(\mathrm{t})+L_{m o} Y_{o}, \\
& \text { and } \\
& K_{m o}=R_{1}^{-1} B^{T} R_{m o}, \\
& L_{m o}=-R_{1}^{-1} B^{T}\left[\left(A-B R_{1}^{-1} B^{T} R_{m o}\right)^{T}\right]^{-1} \\
& C^{T} Q \text {, }
\end{aligned}
$$

where $K_{m o}$ is the optimal feedback gain, $L_{m o}$ is the optimal input gain, $Y_{o}$ is the reference command. The $R_{\text {mo }}$ matrix is obtained by solving the Riccati equation:

$-R_{m o} A-A^{T} R_{m o}+R_{m o} B R_{1}^{-1} B R_{m o}{ }^{-}$ $C^{T} R_{1} C=0$,

where $R_{m o}$ is a symmetric matrix which is obtained from the above Riccati equation.

\section{MINIMIZED SWITCHING FREQUENCY}

For a balanced three-phase drive system which has no neutral line, the three-phase current can be expressed as

$$
i_{a}+i_{b}+i_{c}=0 \text {, }
$$

Because the sum of the three-phase currents is equal to zero, we can determine one phase current when the other two phase currents are regulated. As a result, we can only adjust two legs and set the upper switch or the lower switch of the third leg without any change. However, this fixed switching leg should be changed sequentially and the relationship between the changed legs is shown in Fig. 3. When the phase voltage reaches its maximum value, its related upper switch is closed; however, when the phase voltage reaches its minimum value, its related lower switch is closed. Each related switch is conducted for 60 electrical degrees. In this study, we use only current sensors. Therefore, we have to compute the angle of the voltage vector to determine the modified current commands. The angle is expressed as:

$$
\theta_{e}=\tan ^{-1}\left(i_{q} L_{q} \quad \omega_{r} /\left(i_{q} \mathrm{r}+K_{e} \quad \omega_{r}\right)\right),
$$

where $\theta_{e}$ is the phase angle of the voltage vector, $i_{q}$ is the q-axis current, $L_{q}$ is the q-axis inductance, $\omega_{r}$ is the mechanical speed, and $r$ is the stator resistance. For example, when electrical angle is between 0 and 60 degrees, the lower switch of the c-phase is conducted. When it is between 60 and 120 degrees, the upper switch of the a-phase is conducted. The other cases can be seen in Fig. 3. By using this method, the average switching frequency is reduced to about $70 \%$.

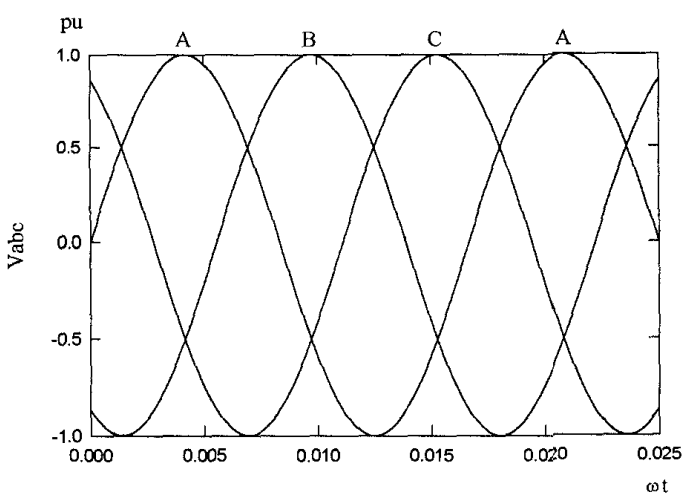

(a)

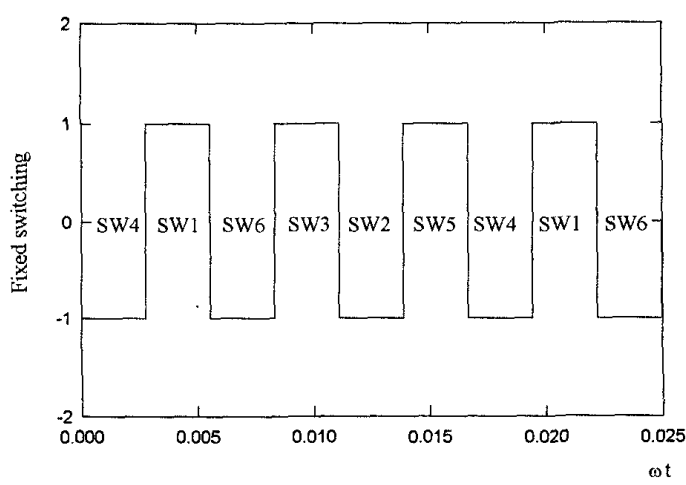

(b)

Fig. 3 The fixed switching sequence (a)voltage (b)sequence.

\section{EXPERIMENTAL RESULTS}

Some experimental results are shown here. Fig. 4 shows the resonant output voltage. Fig. 5 (a) shows the measured a-phase current command. Fig. 5(b) shows the measured a-phase real current. Fig. 6(a) and (b) are the measured line voltages of the traditional method and proposed method. Fig. 7(a) is the measured transient speed response. Fig. $7(\mathrm{~b})$ is the measured load disturbance rejection response. Fig. 8 is the measured total efficiency of the whole system. Fig. 9 is the measured low speed response. Fig. 10 is the measured position response. The experimental results show that the proposed system can achieve both speed control and position control with the satisfied performance. 


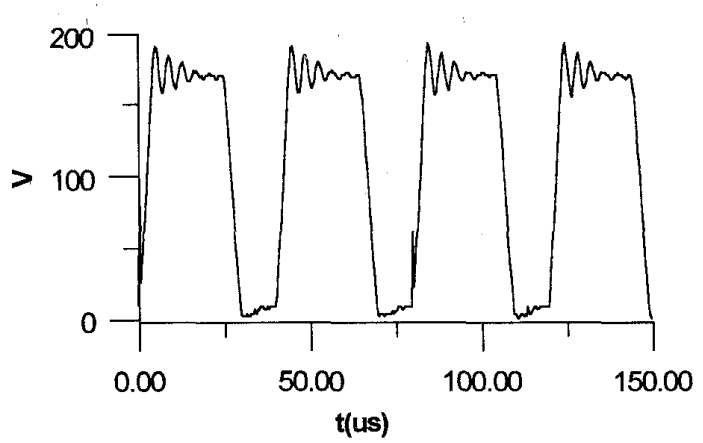

Fig. 4 The measured output voltage of the resonant dc-

link converter.

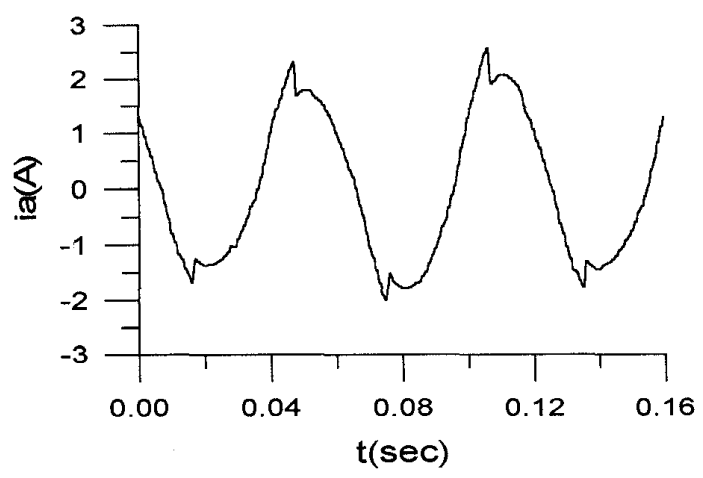

(a)

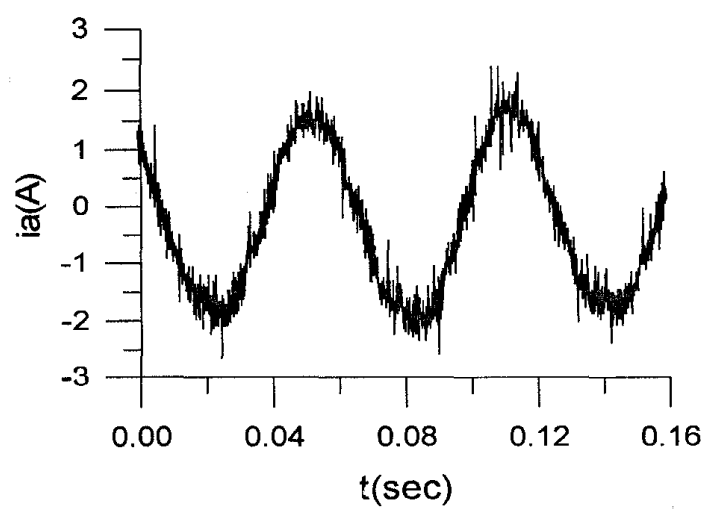

(b)

Fig. 5 The measured phase current

(a) command (b) real current.

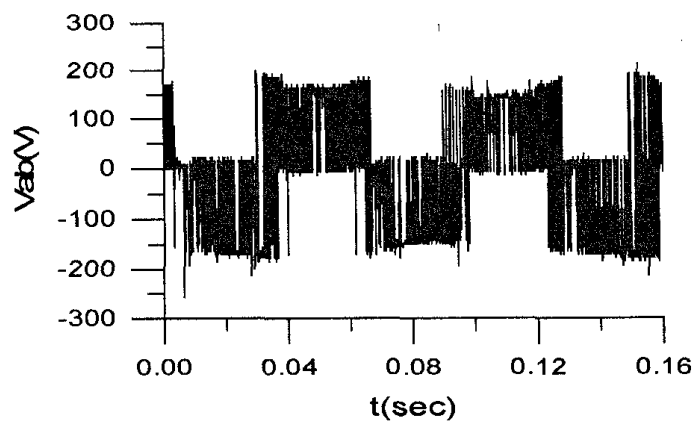

(a)

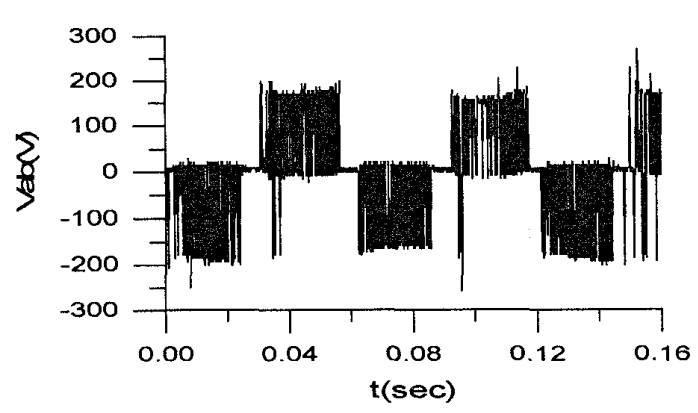

(b)

Fig. 6 The measured line voltage (a) traditional (b)proposed.

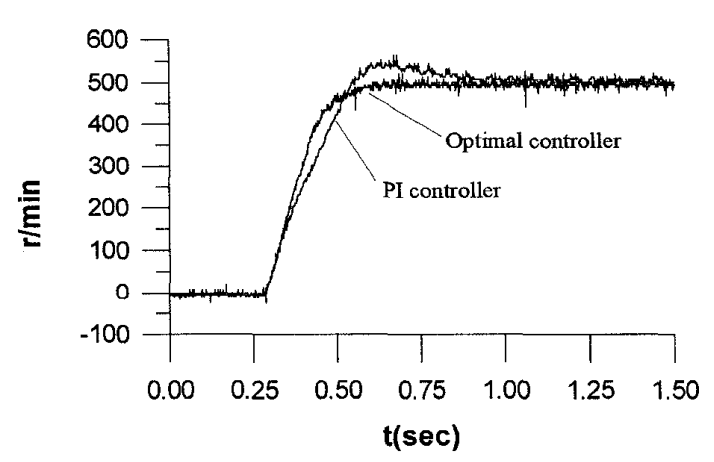

(a) 


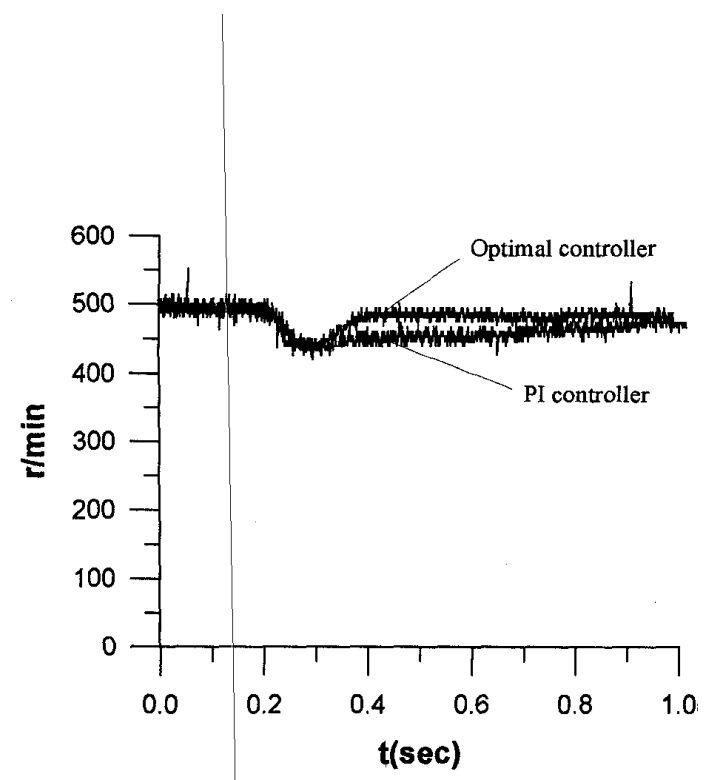

(b)

Fig. 7 The measured speed responses

(a) transient (b) load disturbance.

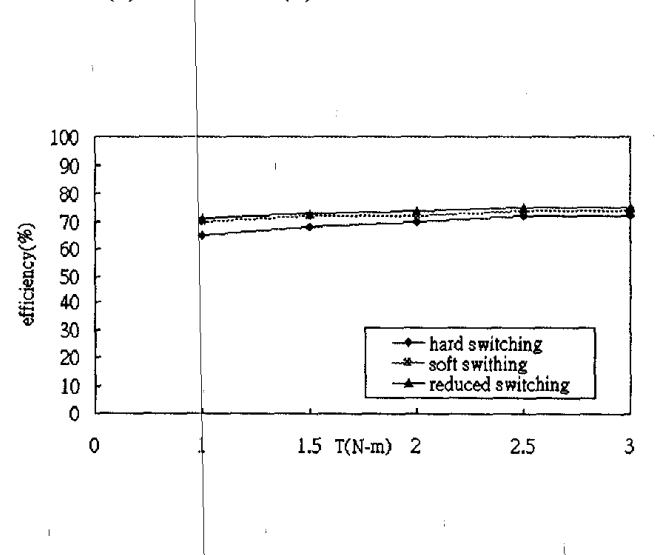

Fig. 8 The measured efficiency.

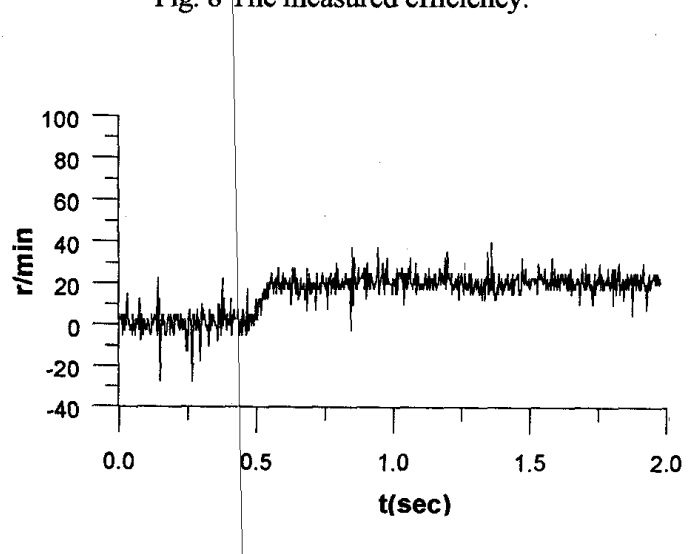

Fig. 9 The measured low speed response $(20 \mathrm{r} / \mathrm{min})$

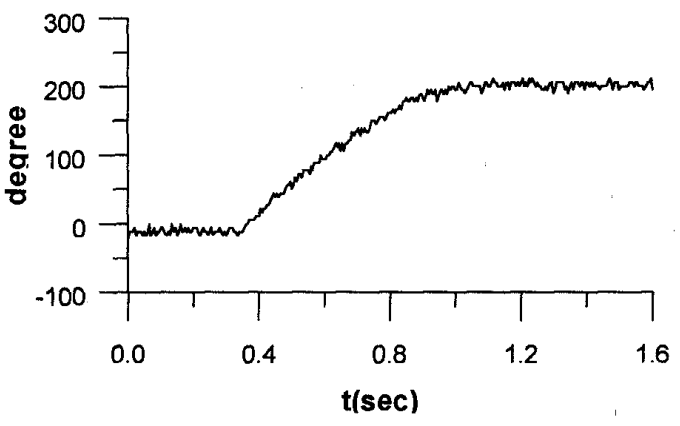

Fig. 10 The measured position response.

\section{ACKNOWLEDGMENT}

This research is supported by the National Science Council, under grant NSC 86-2213-E011-039.

\section{REFERENCES}

[1] S. Morimoto, M. Sanada, and Y. Takada, "Widespeed operation of interior permanent magnet synchronous motors with high-performance current regulator," IEEE Trans. on Ind. Appl, , vol. 30, no. 4, pp. 920-926, July/Aug. 1994.

[2] T. Sebastian and V. Gangla, "Analysis of induced EMF waveforms and torque ripple in a brushless permanent magnet machine," IEEE Trans. on Ind. Appl., vol. 32, no. 1, pp. 195-200, Jan./Feb. 1996.

[3] W. L. Soong, D. A. Saton, and T. J. E. Miller, "Design of a new axilly-laminated interior permanent magnet motor," IEEE Trans. on Ind. Appl., vol. 31, no. 2, pp. 358-367, Mar./ Apr. 1995.

[4] L. Xu, L. Ye, Li Zhen, and A. E. Antably, “A new design concept of permanent magnet machine for flux weakening operation," IEEE Trans. on Ind. Appl., vol. 31, no. 2, pp. 373-378, Mar./Apr. 1995.

[5] D. M. Divan, "The de resonant link converter -a new concept in static power conversion," IIEEE Trans. Ind. Appl., vol. 25, no. 2, pp. 317-325, Mar./Apor. 1989.

[6] D. M. Divan and G. Skibinski, "Zero-switching-loss inverter for high-power application," IEEE Trans. Ind. Appl., vol. 25, no. 4, pp. 634-643, July/Aug. 1989. 